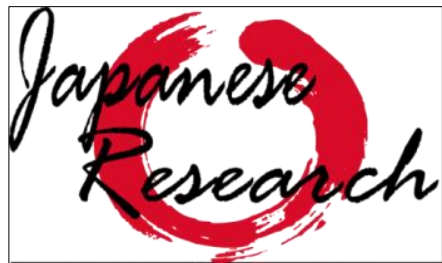

on Linguistics, Literature and Culture
Japanese Research on Linguistics, Literature, and Culture

Vol. 2 No. 2 May 2020, Hal. 161-177 ISSN online: 2655-4836

Doi: $10.33633 /$ jr.v2i2.3990

http://publikasi.dinus.ac.id/index.php/jrllc/article/view/3990/2028

japanese.research@fib.dinus.ac.id

Published by Universitas Dian Nuswantoro, Semarang

\title{
Studi Metafora Konseptual pada Idiom Bahasa Jepang yang Mengandung Bagian Tubuh dan Bermakna Emosi
}

\author{
Nadhira Shafa Ghassani, Akhmad Saifudin \\ Universitas Dian Nuswantoro \\ Universitas Dian Nuswantoro \\ 312201600619@mhs.dinus.ac.id
}

Article History: Submitted date 2020-08-24; Accepted date 2020-09-01; Published date 2020-09-02

\begin{abstract}
Kanyouku is used to express human emotions. This study discusses the mapping of the meaning of Japanese idiom related to emotions in human cognition by using Knowles and Moon's metaphor theory and conceptual metaphor theory by Lakoff and Johnson. The study utilizes 28 idioms that related to human basic emotions such as anger, happiness, sadness, fear, love, shame, pride, and surprise. These basic emotions are obtained from Goo Jiten online Japanese dictionary. The results show that human cognition viewing emotion concept as an entity and representing emotions into human body. In Japanese people's cognition, anger represented as belly, chest, and head; fear represented as tongue, heart, and foot; happiness represented as cheek, chest, and heart; sadness represented as shoulder, chest, and heart; love represented as eye and heart; pride represented as chest; shame represented as face and cheek; and surprise represented as eye, tongue, and heart. Human cognition represented emotion concept as human body to measure the level of emotion. This study mapped the emotion concepts as a concrete entity: the entity as fluid in a container or entity as parts of body.
\end{abstract}

Keywords: cognitive linguistic, conceptual metaphor, image scheme, idiom, emotion

\begin{abstract}
Abstrak
Kanyouku digunakan untuk mengungkapkan emosi seseorang. Penelitian ini bertujuan untuk memetakan kognisi manusia terhadap makna kanyouku yang berkaitan dengan emosi berdasarkan teori metafora oleh Knowles dan Moon dan teori metafora konseptual oleh Lakoff dan Johnson. Data diperoleh sebanyak 28 data dari kamus idiom Jepang online Goo Jiten yang memiliki makna berkaitan dengan emosi dasar manusia yaitu marah, senang, sedih, takut, cinta, malu, bangga, dan terkejut. Hasil analisis memetakan konsep emosi sebagai entitas dan merepresentasikan konsep emosi manusia sebagai bagian tubuh manusia. Pemetaan kognitif orang Jepang memetakan emosi marah yang direpresentasikankan dengan bagian perut, dada, kepala; emosi takut yang direpresentasikan dengan bagian tubuh yaitu lidah, hati, dan kaki; emosi senang yang
\end{abstract}


direpresentasikan dengan pipi, dada, dan hati; emosi sedih yang direpresentasikan dengan bagian tubuh yaitu bahu, dada, dan hati; emosi cinta yang direpresentasikan dengan mata dan hati; emosi bangga yang direpresentasikan dengan dada; emosi malu yang direpresentasikan dengan wajah dan pipi; dan emosi terkejut yang direpresentasikan dengan mata, lidah, dan jantung. Pemetaan konsep emosi yang bersifat abstrak ke dalam bagian tubuh bertujuan untuk menunjukkan tingkat emosi yang dialami agar lebih mudah dipahami karena lebih terukur. Hal ini memetakan emosi yang bersifat abstrak sebagai sebuah entitas yang konkret yaitu entitas berupa cairan yang terdapat di dalam wadah atau entitas berupa organ tubuh.

Kata Kunci: linguistik kognitif, metafora konseptual, skema citra, idiom, emosi

\section{Pendahuluan}

Japanese Idiom merupakan salah satu bagian dari bahasa. Seluruh bahasa yang ada di dunia ini memiliki idiom, termasuk bahasa Jepang. Idiom dalam bahasa Jepang disebut kanyouku (慣用句). Idiom terdiri dari dua kata atau lebih yang maknanya tidak dapat diprediksikan hanya melalui tiap-tiap unsur kata penyusunnya (Kovecses, 2010: 231). Muneo (1992) mengatakan, idiom banyak digunakan dalam kalimat dan percakapan sehari-hari. Biasanya berupa kata-kata yang singkat. Namun, apabila disesuaikan dengan waktu dan tempat, maka hal itu akan memperkaya bahasa dan mengekspresikan kalimat dan percakapan agar terasa hidup. Salah satu fungsi kanyouku yaitu media untuk mengungkapkan tingkat kedalaman emosi seseorang, baik emosi yang berkonotasi positif seperti suka, bahagia, senang, cinta, dan sebagainya, maupun emosi yang berkonotasi negatif seperti marah, benci, sedih, dan sebagainya. Selain itu, kanyouku juga dapat digunakan untuk memperhalus suatu ucapan agar tidak menyinggung lawan bicara (Rahmah, t.thn: 3). Namun, idiom tidak dapat dipahami maknanya hanya melalui kata penyusunnya saja sehingga pelajar asing bahasa Jepang sering mengalami kendala dalam memahami makna idiom padahal idiom sering digunakan oleh penutur bahasa Jepang untuk berkomunikasi.

Kovecses (2010:233) menyebutkan bahwa, kebanyakan idiom bukan hanya sekadar bahasa tetapi hasil dari sistem konseptual manusia, makna idiom memiliki hubungan erat dengan pengetahuan dan sistem konseptual manusia. Lebih lanjut Kovecses (2010:233) mengatakan pemaknaan idiom dapat dilakukan dengan mekanisme kognitif berupa metafora, metonimi, dan pengetahuan konvensional. Pada penelitian ini, peneliti terfokus pada pemaknaan idiom 
menggunakan teori metafora konseptual yang dikemukakan oleh Lakoff dan Johnson (1980) dan teori metafora oleh Knowles dan Moon (2006). Penelitian ini bertujuan untuk memetakan kognisi manusia terhadap makna idiom bahasa Jepang yang berkaitan dengan emosi menggunakan teori metafora oleh Knowles dan Moon (2006) dan teori metafora konseptual yang dikemukakan oleh Lakoff dan Johnson (1980).

Dalam penelitian ini dibahas pemetaan kognisi manusia terhadap makna idiom bahasa Jepang yang berkaitan dengan emosi dasar manusia yaitu marah, takut, senang, sedih, cinta, bangga, malu, dan terkejut berdasarkan teori metafora oleh Knowles dan Moon (2006) dan teori metafora konseptual oleh Lakoff dan Johnson (1980).

\section{Kajian Teoretis}

Metafora dalam bahasa Jepang disebut 隠喻 In'yu. Metafora mengandung hubungan antara source domain (makna sebenarnya pada ekspresi metafora) dan target domain (pengalaman yang digambarkan dengan metafora) (Croft \& Cruse, 2004:55). Knowles dan Moon (2006:2) juga mengatakan bahwa metafora adalah penggunaan bahasa yang merujuk pada sesuatu yang lebih dari pada makna harfiahnya agar terbentuk suatu hubungan antara dua hal yang memiliki beberapa kemiripan. Menurut Knowles dan Moon (2006:7) terdapat tiga elemen yang diperlukan untuk mengidentifikasi metafora, yaitu (1) vehicle (metafora berupa kata atau frase); (2) topic/tenor (makna metaforis); (3) grounds (hubungan dan persamaan antara makna metaforis dan makna literal). Lakoff dan Johnson (1980:3-6) menyatakan metafora bukan hanya bentuk bahasa figuratif yang digunakan untuk menciptakan imajinasi puitis dalam karya sastra saja, melainkan metafora juga berperan dalam kehidupan manusia sehari-hari. Metafora bukan hanya berperan sebagai bahasa, tetapi pemikiran dan tindakan manusia juga. Sistem konseptual manusia seperti cara berpikir, pengalaman, dan tindakan sebagian besar terdiri atas metafora. Sebab apa yang dilakukan oleh manusia, apa yang dipikirkan oleh manusia, dan apa yang dialami

oleh manusia adalah bentuk dari metafora, yang kemudian disebut metafora konseptual. Lakoff dan Johnson (1980) membagi metafora konseptual menjadi 3 jenis, yaitu (1) metafora struktural yang menghubungkan sebuah konsep dengan konsep lain yang didasarkan pada kemiripan struktur atau sistem; (2) metafora orientasional yang berhubungan dengan orientasi spasial 
(naik-turun, dalam-luar, depan-belakang, dll.); dan (3) metafora ontologikal yang menyatakan hal abstrak (peristiwa, aktivitas, emosi, gagasan, dll.) sebagai entitas dan substansi.

Metafora konseptual berkaitan dengan skema citra. Menurut Johnson dalam Gruyter (2005:15), skema citra dari segi filosofis memiliki peran yang penting karena dapat membantu untuk menjelaskan bagaimana pemikiran manusia mampu berpikir abstrak sekaligus mewujudkannya. Skema citra juga memainkan peran penting pada pola sensorik-motorik manusia sehingga pemikiran manusia dapat memaknai dan memiliki kemampuan penalaran konseptualisasi abstrak yang didasarkan pada interaksi tubuh manusia dengan lingkungan. Cruse dan Croft (2004:45) menyebutkan daftar skema citra sebagai berikut: up-down, front-back, leftright, near-far, center-periphery, contact, path, containtment, in-out, surface, full-empty, content, balance, counterforce, compulsion, restrain, enablement, blockage, diversion, attraction, merging, collection, splitting, iteration, part-whole, mass-count, link, matching, superimposition, removal, bounded.

\section{Metode Penelitian}

\subsection{Sumber Data}

Data dikumpulkan dari beberapa sumber. Sumber data utama berupa kamus idiom bahasa Jepang online Goo Jiten. Sumber data pendukung didapatkan dari portal berita Jepang seperti NHK, Asahi Shimbun, Yahoo News, Imidas dan lain-lain. Data yang diidentifikasi berupa ungkapan atau frasa berupa Idiom bahasa Jepang yang terbentuk dari anggota tubuh yang maknanya berkaitan dengan emosi.

\subsection{Satuan Analisis}

Data yang digunakan adalah ungkapan atau frasa berupa idiom bahasa Jepang tersebut terbentuk dari anggota tubuh yang maknanya berkaitan dengan emosi yang terdapat pada kamus online Goo Jiten.

\subsection{Teknik Pengumpulan dan Analisis}

Teknik pengumpulan data yang dilakukan pada penelitian ini adalah dengan observasi sumber data berupa kamus idiom bahasa Jepang online Goo Jiten. Kemudian, peneliti mengumpulkan ungkapan atau frasa berupa Idiom bahasa Jepang tersebut terbentuk dari 
anggota tubuh yang maknanya berkaitan dengan emosi. Ada pun langkah-langkah yang dilakukan dalam pengumpulan dan analisis data dijelaskan secara rinci sebagai berikut:

1) Mencari idiom bahasa Jepang yang terbentuk dari anggota tubuh pada kamus idiom bahasa Jepang online Goo Jiten.

2) Mengumpulkan idiom bahasa Jepang yang memiliki makna berkaitan dengan emosi.

3) Mengkategorisasi idiom bahasa Jepang berdasarkan jenis anggota tubuh sesuai daftar anggota tubuh pada kamus bahasa Jepang online Weblio.

4) Menentukan data dan jumlah data yang dianalisis berdasarkan persentase $30 \%$ dari jumlah keseluruhan data idiom pada setiap jenis emosi dasar manusia.

5) Mencari contoh kalimat yang mengandung idiom bahasa Jepang yang berkaitan dengan emosi pada portal berita Jepang seperti NHK, Asahi Shimbun, Yahoo News, Imidas, dan lain-lain.

6) Mengidentifikasi idiom dan maknanya berdasarkan kamus bahasa Jepang online Goo Jiten dari contoh kalimat yang ditemukan.

7) Mengidentifikasi makna leksikal unsur pembentuk idiom dengan menggunakan kamus Kokugo Jiten.

8) Membandingkan makna leksikal dan kontekstual dari idiom bahasa Jepang yang berkaitan dengan emosi.

9) Memetakan pemikiran manusia dengan idiom bahasa Jepang yang berkaitan dengan emosi berdasarkan teori metafora konseptual yang dikemukakan oleh Lakoff dan Johnson dan teori pemahaman metafora yang dikemukakan oleh Knowles dan Moon.

\section{Hasil dan Pembahasan}

\subsection{Metafora Konseptual pada Idiom Emosi Marah}

Data 1

頭から湯気を立てる (atama kara yuge wo tateru) 'muncul uap dari kepala' Idiom atama kara yuge wo tateru terdapat pada kalimat 1a:

(1a) その結果を知ると、日ごろ温厚な先生も、頭から湯気を立てて怒った。 Sono kekka wo shiru to, higoro onkou na sensei mo, atama kara yuge wo tatete okotta. 'Kalau mengetahui hasilnya begitu, guru yang kalem sekali pun akan marah-marah.'

Analisis data 1

(Sumber: https://imidas.jp/) 
Makna metaforis/Topic : Marah

Hubungan/Ground

: Emosi marah merupakan cairan yang mendidih di dalam kepala sehingga menimbulkan uap.

Makna harfiah atama kara yuge wo tateru adalah muncul uap dari kepala, sedangkan makna metaforisnya adalah marah. Atama kara yuge wo tateru merupakan frasa metaforis (vehicle) yang memiliki makna metaforis (topic) yaitu marah. Hal ini didasarkan pada hubungan antara makna harfiah dan makna metaforisnya yang dihubungkan dengan metafora ontologikal dan metafora orientasional.

Metafora ontologikal menjelaskan konsep emosi marah sebagai sebuah objek berupa cairan yang mendidih di dalam wadah yaitu kepala. Konsep pemikiran manusia memetakan emosi marah yang sifatnya abstrak dan tidak memiliki acuan menjadi bentuk benda yang dapat memenuhi isi kepala yang mendidih seperti cairan. Kepala memiliki skema citra berupa container sebagai wadah yang menampung emosi dan emosi sebagai entitas berbentuk cairan yang panas. Kepala merupakan bagian pusat rasionalitas seseorang. Manusia akan kehilangan pemikiran rasionalnya apabila emosi marah yang berasal dari perut tiba di kepala. Emosi marah yang sudah berada di dalam kepala akan semakin memuncak (mendidih) apabila dipicu oleh rangsangan yang memicu kemarahan yang luar biasa. Ketika emosi marah sudah berada di kepala, maka kemarahan sudah berada di puncaknya. Emosi marah yang mendidih di dalam kepala sebelum diledakkan serupa seperti gunung berapi yang siap meletus, emosi marah diibaratkan seperti lahar yang mengeluarkan asap pada kawah gunung. Oleh karena itu, kepala merepresentasikan kemarahan karena emosi marah berada di kepala ketika kemarahan seseorang sudah berada di puncaknya.

Metafora orientasional pada idiom atama kara yuge wo tateru 'muncul uap dari kepala' kepala dan emosi marah dengan orientasi spasial berupa in-out (dalam-luar). Orientasi spasial inout memetakan konsep emosi marah yang mendidih di dalam kepala menghasilkan uap dari dalam kepala sehingga timbul di atas kepala. Uap merupakan efek yang timbul akibat sesuatu yang panas, misalnya pada cairan yang mendidih. Pergerakan uap yang berasal dari dalam kepala memiliki skema citra path dan space. Emosi marah yang mendidih di dalam kepala seseorang sehingga menimbulkan uap di luar kepala memiliki skema citra space berupa out. Bagian dalam kepala tempat uap bermula dicitrakan sebagai source dan bagian luar kepala tempat keluarnya 
uap dicitrakan sebagai sebagai goal. Oleh karena itu, emosi marah diibaratkan sebagai cairan panas yang mengisi kepala seseorang ketika kemarahannya sudah berada di puncak sehingga merepresentasikan uap yang muncul dari kepala.

Berdasarkan analisis data 1 yang telah diuraikan sebelumnya, dapat disimpulkan bahwa metafora pada idiom atama kara yuge wo tateru memetakan marah sebagai emosi yang bergejolak dan mendidih di dalam kepala sehingga menghasilkan uap yang muncul dari kepala ketika seseorang sedang berada di puncak kemarahan.

\subsection{Metafora Konseptual pada Idiom Emosi Senang}

Data 3

胸が晴れる (mune ga hareru) 'dada cerah' Idiom mune ga odoru terdapat pada kalimat 3a:

言いたいことを言ったので、胸が晴れる。

litai koto wo itta node, mune ga hareru.

'Rasanya lega karena telah mengatakan apa yang ingin disampaikan.'

Analisis data 3

(Sumber: https://dictionary.goo.ne.jp/)

Frase metafora/Vehichle Makna metaforis/Topic Hubungan/Ground

\author{
: Mune ga hareru \\ :Senang \\ : Beban berupa kesedihan, kekhawatiran, dan sebagainya diibaratkan \\ sebagai awan yang menyelimuti perasaan seseorang.
}

Makna harfiah mune ga hareru adalah dada cerah, sedangkan makna metaforisnya adalah senang. Mune ga hareru merupakan frasa metaforis (vehicle) yang memiliki makna metaforis (topic) yaitu senang. Hal ini didasarkan pada hubungan antara makna harfiah dan makna metaforisnya yang dihubungkan dengan metafora ontologikal dan metafora struktural.

Metafora ontologikal menjelaskan konsep emosi senang sebagai sebuah objek yang berada di dalam wadah yaitu dada. Konsep pemikiran manusia memetakan emosi senang yang sifatnya abstrak dan tidak memiliki acuan menjadi sesuatu wujud yang terdapat di dalam suatu wadah dan menyerupai cuaca. Mune dinyatakan sebagai entitas atau wadah dan rongga emosi (Berendt dan Tanita, 2011:73) sehingga dada memiliki skema citra berupa container berupa wadah yang menampung emosi dan emosi dan sebagai entitas yang terdapat di dalamnya. Emosi manusia yang berada di dalam dada diibaratkan sebagai cuaca seperti hujan, mendung, cerah, dan sebagainya. Oleh karena itu, dada merepresentasikan emosi senang karena dada merupakan wadah emosi senang yang dialami seseorang. 
Metafora struktural juga menghubungkan emosi seseorang dengan cuaca. Ketika seseorang merasa sangat senang terhadap suatu hal, maka ibaratnya sama seperti ketika mentari bersinar terang. Emosi senang dan matahari memiliki keterkaitan karena ketika cuaca cerah, manusia cenderung merayakannya dengan kebahagiaan misalnya liburan musim panas, berjemur di tepi pantai, dan kegiatan yang menyenangkan lainnya. Sebaliknya, cuaca mendung atau hujan juga memiliki keterkaitan dengan emosi sedih karena cuaca buruk cenderung membuat orang memiliki emosi negatif seperti marah, kesal, khawatir karena pada cuaca buruk manusia cenderung membatalkan rencana kegiatannya, membuat pakaian yang sudah dipersiapkan serapi mungkin menjadi basah kuyup, banyak petir menyambar dan sebagainya. Ketika seseorang mempunyai beban di dalam benaknya, ia cenderung akan bersikap murung, sedih, khawatir, kesal, dan sebagainya, sehingga hal ini membuat suasana hati seseorang seperti mendung tertutup oleh kabut atau awan. Namun, ketika seseorang telah melepaskan beban yang ada di dalam benaknya, maka hal itu seolah menghilangkan awan yang ada di dalam dadanya dan suasana hatinya menjadi cerah. Emosi senang dan cuaca cerah menciptakan skema citra berupa link yaitu keterkaitan antara cuaca dan suasana hati seseorang. Oleh karena itu, emosi senang diibaratkan sebagai sesuatu yang cerah karena beban di dalam hati yang sifatnya seperti kabut atau awan menghilang.

Berdasarkan analisis data 3 yang telah diuraikan sebelumnya, dapat disimpulkan bahwa metafora pada idiom mune ga hareru memetakan emosi senang sebagai emosi yang memiliki keterkaitan dengan cuaca cerah karena kesedihan, kekhawatiran, dan beban yang serupa dengan kabut dan awan tidak lagi menyelimuti benak seseorang.

\subsection{Metafora Konseptual pada Idiom Emosi Sedih}

Data 4

心が沈む (kokoro ga shizumu) 'hati tenggelam' Idiom kokoro ga shizumu terdapat pada kalimat 4a:

(4a) 親友の訃報を聞いて、今日は一日じゅう心が沈んだ。 Shinyuu no fuhou wo kiite, kyou wa ichijou kokoro ga shizunda. 'Hari ini, aku murung seharian karena mendengar berita kematian sahabatku.'

(Sumber: https://imidas.jp/) 
Analisis data 4

Frase metafora/Vehichle Makna metaforis/Topic Hubungan/Ground

\begin{abstract}
: Kokoro wo shizumu
: Sedih

: Seseorang yang tenggelam dalam kesedihan cenderung hanya memikirkan kesedihannya karena jarak pandangnya pendek dan tekanan dalam dirinya sangat besar seperti orang yang sedang tenggelam.
\end{abstract}

Makna harfiah kokoro ga shizumu adalah hati tenggelam, sedangkan makna metaforisnya adalah sedih. Kokoro ga shizumu merupakan frasa metaforis (vehicle) yang memiliki makna metaforis (topic) yaitu sedih. Hal ini didasarkan pada hubungan antara makna harfiah dan makna metaforisnya yang dihubungkan dengan metafora ontologikal dan metafora orientasional.

Metafora ontologikal menjelaskan konsep emosi sedih sebagai sebuah objek yang berada dalam benak atau hati seseorang. Konsep pemikiran manusia memetakan emosi sedih yang sifatnya abstrak dan tidak memiliki acuan berupa suatu benda yang terdapat di dalam suatu wadah. Hati memiliki skema citra container sebagai wadah emosi dan emosi sedih sebagai entitas yang terdapat di dalam wadah. Hati merupakan bagian dalam tubuh seseorang yang mewadahi akal, pikiran, perasaan, dan emosi seseorang. Emosi yang ada di dalam hati bermacam-macam dapat berupa emosi senang, emosi sedih, emosi marah, emosi malu, dan lain sebagainya. Oleh karena itu, hati merepresentasikan emosi sedih karena emosi terdapat di dalam hati.

Metafora orientasional pada idiom kokoro ga shizumu 'hati tenggelam' menghubungan hati dan emosi sedih dengan orientasi spasial berupa down. Orientasi spasial down memetakan konsep emosi sedih yang ada pada hati menenggelamkan perasaan seseorang. Emosi sedih diumpamakan sebagai air yang bisa dijadikan sarana suatu benda untuk mengambang atau tenggelam. Ketika seseorang tenggelam, maka tekanan pada tubuhnya akan menjadi besar sedangkan ketika ia mengambang, tekanan yang didapatkan oleh tubuhnya pun kecil. Selain itu, jarak pandang ketika seseorang tenggelam pun menjadi pendek tidak seperti ketika berada di daratan. Jika diumpamakan emosi sedih adalah lautan atau permukaan air yang menenggelamkan hati yang berisi akal, pikiran, perasaan, dan tekad, maka emosi sedih tersebut menekan perasaan yang ada di dalam hati dan membatasi jarak pandangnya sehingga membuat seseorang cenderung hanya fokus pada kesedihannya padahal di depannya terdapat titik terang. Hal ini memiliki skema citra force dan space, skema citra force dengan ciri compulsion memberikan gambaran ketika kesedihan menenggelamkannya maka tekanan pun akan semakin 
besar sedangkan skema citra space dengan ciri down menggambarkan arah benda yang tenggelam menuju ke dasar atau ke bawah.

Berdasarkan analisis data 4 yang telah diuraikan sebelumnya, dapat disimpulkan bahwa metafora pada idiom kokoro wo shizumu memetakan emosi sedih sebagai emosi berupa cairan yang menenggelamkan hati yang berisi akal, pikiran, perasaan, dan emosi sehingga memberi tekanan kuat dan membuat hati seseorang dihimpit oleh kesedihan.

\subsection{Metafora Konseptual pada Idiom Emosi Cinta}

\section{Data 5}

目がない (me ga nai) 'Tidak punya mata' Idiom me ga nai terdapat pada kalimat 5a:

(5a) 食生活の乱れも自覚している。お酒は飲むし、揚げ物も好き。さらに、高コレステロー ル食品とされる魚卵には目がない。

Shokuseikatsu no midaremo jikakushiteiru. Osake wa nomu shi, agemono mo suki. Sara ni, kou koresuterooru shokuhin to sareru gyoran ni wa me ga nai.

'Saya menyadari kebiasaan makan yang tidak terkontrol. Saya suka minum sake dan makan gorengan. Terlebih lagi, saya tergila-gila dengan makanan yang mengandung kolesterol tinggi seperti telur ikan.'

(Sumber: https://headline.yahoo.co.jp/)

Analisis data 5

Frase metafora/Vehichle

Makna metaforis/Topic

Hubungan/Ground

: Me ga nai

: Cinta

: Sama seperti istilah "cinta itu buta", logika seseorang dikalahkan oleh perasaan suka sehingga membuat seseorang tidak dapat melihat kebaikan dan keburukan terhadap hal yang disukainya.

Makna harfiah me ga nai adalah tidak punya mata, sedangkan makna metaforisnya adalah cinta. Me ga nai merupakan frasa metaforis (vehicle) yang memiliki makna metaforis (topic) yaitu cinta. Hal ini didasarkan pada hubungan antara makna harfiah dan makna metaforisnya yang dihubungkan dengan metafora ontologikal dan metafora struktural.

Metafora ontologikal menjelaskan konsep emosi cinta sebagai sebuah objek yang diekspresikan oleh mata. Mata merupakan jendela hati yang mana isi hati dapat diekspresikan melalui sorot pandangan mata. Konsep pemikiran manusia memetakan emosi cinta yang sifatnya abstrak dan tidak memiliki acuan menjadi suatu penyebab yang berhubungan erat dengan mata. Mata memiliki skema citra berupa surface berupa permukaan transparan yang dapat melihat isi hati seseorang karena emosi seperti senang, sedih, cinta, takut, merupakan suatu hal yang dapat dilihat melalui mata seseorang. Maka dari itu, mata merepresentasikan emosi cinta dalam bentuk 
ekspresi yang menyebabkan seseorang tidak dapat melihat kebaikan atau keburukan suatu hal yang dicintainya. Namun, selain berhubungan dengan perasaan, mata juga berhubungan dengan logika. Sebagaimana menurut kamus kokugo jiten, mata merupakan indera penglihatan untuk mengetahui keadaan sekitar. Apabila seseorang tidak memiliki mata berarti seseorang tersebut buta. Jika diterjemahkan secara harfiah, me ga nai yang berarti tidak punya mata atau buta tidak ada kaitannya dengan cinta. Oleh karena itu, idiom me ga nai juga melibatkan metafora struktural di dalamnya.

Metafora struktural pada idiom me ga nai 'tidak punya mata' menghubungan mata dan emosi cinta berupa persamaan sifat antara cinta dan buta. Ketika seseorang cinta terhadap suatu hal, ia tidak bisa melihat atau tidak mau mengetahui baik atau buruknya suatu hal yang ia sukai. Hal ini berkaitan dengan kebutaan yang mana ketika seseorang tidak dapat melihat keadaan sekitarnya. Seperti pada contoh kalimat 5a, seseorang sangat menyukai makanan berkolesterol tinggi padahal ia tahu kalau itu adalah kebiasaan makan yang tidak terkontrol atau tidak baik karena dapat menyebabkan penyakit jantung tetapi ia tetap sangat menyukainya tanpa peduli dampak daripada mengkonsumsi makanan tinggi kolesterol tersebut. Oleh karena itu, mata merepresentasikan emosi cinta karena seseorang yang sangan mencintai sesuatu hal cenderung tidak bisa menilai hal yang ia cintai dengan bijak seperti tidak punya mata (buta).

Berdasarkan analisis data 5 yang telah diuraikan sebelumnya, dapat disimpulkan bahwa metafora pada idiom me ga nai memetakan emosi cinta sebagai emosi yang menyebabkan seseorang menjadi "buta” karena tidak bisa menilai sesuatu hal dengan bijak.

\subsection{Metafora Konseptual pada Idiom Emosi Bangga}

Data 6

胸を張る (mune wo haru) 'menonjolkan dada' Idiom mune ga odoru terdapat pada kalimat 6a:

(6a) そう胸を張るために、このモットーが掲げられてきました。 Sou mune wo haru tame ni, kono mottoo ga kakagerarete kimashita.

'Motto ini dipublikasikan demi suatu kebanggaan.'

Analisis data 6

Frase metafora/Vehichle Makna metaforis/Topic

: Mune wo haru

Hubungan/Ground

: Bangga

: Dada diibaratkan sebagai sesuatu yang dibanggakan sehingga mencondongkannya untuk memamerkannya. 
Makna harfiah mune wo haru adalah menonjolkan dada, sedangkan makna metaforisnya adalah bangga. Mune wo haru merupakan frasa metaforis (vehicle) yang memiliki makna metaforis (topic) yaitu bangga. Hal ini didasarkan pada hubungan antara makna harfiah dan makna metaforisnya yang dihubungkan dengan metafora ontologikal.

Metafora ontologikal menjelaskan konsep emosi bangga sebagai sebuah objek yang terdapat di dalam wadah yaitu dada. Konsep pemikiran manusia memetakan emosi bangga yang sifatnya abstrak dan tidak memiliki acuan menjadi sesuatu wujud yang terdapat di dalam dada. Dada memiliki skema citra container berupa wadah yang terdapat emosi di dalamnya dan emosi sebagai entitas yang terdapat di dalam wadah. Mune dinyatakan sebagai entitas atau wadah dan rongga emosi (Berendt dan Tanita, 2011:73). Emosi bangga yang terdapat di dalam dada seseorang tiimbul ketika seseorang melakukan suatu hal yang membuatnya merasa bangga misalnya seperti melakukan hal yang hebat, mencapai mimpi, mewujudkan keinginannya dan lain-lain. Kebanggaan tersebut memicu emosi bangga untuk meningkatkan kepercayaan diri seseorang. Kepercayaan diri yang semakin bertambah akan membuat sikap tubuh seseorang menjadi tegak sehingga tidak ada orang yang bisa merendahkannya. Sikap tubuh yang tegak karena percaya diri tersebut menyebabkan dada seseorang menjadi lebih bidang dan condong ke depan. Hal ini menunjukkan emosi bangga yang memiliki skema citra berupa attraction yang meningkatkan kepercayaan diri seseorang sehingga sikap tubuhnya menjadi tegak. Oleh karena itu, dada merepresentasikan emosi bangga karena emosi bangga merangsang kepercayaan diri seseorang sehingga mempengaruhi sikap tubuhnya yang cenderung menjadi tegak dan menonjolkan dada.

Berdasarkan analisis data 6 yang telah diuraikan sebelumnya, dapat disimpulkan bahwa metafora pada idiom mune wo haru memetakan emosi bangga sebagai emosi yang merangsang kepercayaan diri seseorang sehingga mempengaruhi sikap tubuhnya dengan mencondongkan dadanya agar menjadi tegak.

\subsection{Metafora Konseptual pada Idiom Emosi Malu}

\section{Data 7}

顔から火が出る (kao kara hi ga deru) 'muncul api dari wajah' Idiom kao kara hi ga deru terdapat pada kalimat 7a:

(7a) 人前で大失敗を演じ顔から火が出る思いがした。 Hitomae de daishippai wo enji kao kara hi ga deru omoi ga shita. 
'Rasanya sangat malu saat melakukan suatu kesalahan besar di muka umum.'

Analisis data 7

(Sumber: https://dictionary.goo.ne.jp/)

Frase metafora/Vehichle

Makna metaforis/Topic

Hubungan/Ground
: Kao kara hi ga deru

: Malu

: Wajah orang yang merasa malu akan menjadi hangat dan merah mirip seperti sifat api

Makna harfiah kao kara hi ga deru adalah muncul api dari wajah, sedangkan makna metaforisnya adalah malu. Kao kara hi ga deru merupakan frasa metaforis (vehicle) yang memiliki makna metaforis (topic) yaitu malu. Hal ini didasarkan pada hubungan antara makna harfiah dan makna metaforisnya yang dihubungkan dengan metafora ontologikal dilengkapi dengan metafora struktural.

Metafora ontologikal menjelaskan konsep emosi malu sebagai objek dan mengekspresikan wajah sebagai suatu permukaan. Konsep pemikiran manusia memetakan emosi malu yang sifatnya abstrak dan tidak memiliki acuan menjadi suatu acuan yang memiliki suhu dan warna. Wajah memiliki skema citra surface berupa permukaan yang menjadi pembatas bagian dalam dan luar pada emosi yang dialami seseorang. Hal ini diibaratkan wajah sebagai sebuah permukaan dan emosi malu sebagai objek yang berada di belakang permukaan tersebut. Lihat pada gambar 4.1.

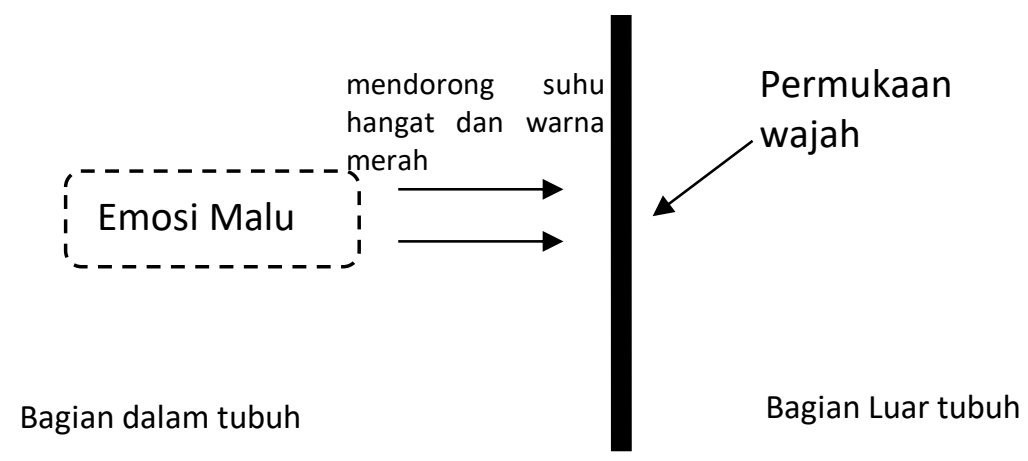

\section{Gambar 4.1. Ilustrasi Emosi Malu dan Wajah}

Wajah merupakan bagian tubuh yang dapat menunjukkan emosi yang dirasakan oleh manusia melalui ekspresi atau raut wajah. Ketika seseorang sedang merasa malu, pembuluh darah pada wajah akan melebar dan memungkinkan aliran darah semakin banyak mengalir ke 
wajah. Hal ini menyebabkan wajah orang yang sedang merasa malu merespon dengan wajah yang menjadi berwarna merah dan cenderung menjadi hangat. Emosi malu memiliki skema citra berupa force dengan ciri emosi malu sebagai compulsion yang mendorong respon suhu hangat dan warna merah agar muncul pada wajah seseorang.

Metafora struktural pada idiom kao kara hi ga deru 'muncul api dari wajah' menghubungan wajah dan emosi malu berupa persamaan sifat antara respon emosi malu dengan api. Jika diterjemahkan secara harfiah, kao kara hi ga deru berarti muncul api dari wajah, sedangkan wajah tidak dapat menyemburkan api dan manusia tidak membakar wajahnya ketika sedang merasa malu. Menurut konsep budaya Jepang, api merupakan suatu kobaran berwarna merah menyala dan sangat panas yang timbul ketika sedang membakar sesuatu. Warna dan suhu pada api merepresentasikan warna merah dan suhu hangat yang timbul pada wajah seseorang ketika sedang merasa malu. Oleh karena itu, wajah merepresentasikan emosi malu karena seseorang yang sedang merasa malu wajahnya cenderung menjadi merah dan hangat mirip seperti sifat api walaupun warna dan suhunya tidak benar-benar sama persis dengan api.

Berdasarkan analisis data 7 yang telah diuraikan sebelumnya, dapat disimpulkan bahwa metafora pada idiom kao kara hi ga deru memetakan malu sebagai emosi yang mendorong respon suhu dan warna yang muncul pada wajah sehingga mirip seperti sifat api.

\subsection{Metafora Konseptual pada Idiom Emosi Terkejut}

Data 8 Shita wo maku

舌を巻く(shita wo maku) 'menggulung lidah' Idiom shita wo maku terdapat pada kalimat 8a:

(8a)招へいした小久保裕紀監督も舌を巻くほどの手腕を発揮した。 Shouheishita Kokubo Yuuki kantoku mo shita wo maku hodo no shuuan wo hakkishita. 'Direktur Kokubo Yuki yang mengundangnya juga tercengang melihat keahliannya.'

Analisis data 8 (Sumber: https://news.yahoo.co.jp/)

Frase metafora/Vehichle Makna metaforis/Topic Hubungan/Ground
: Shita wo maku

: Terkejut

: Ketika merasa terkejut, seseorang cenderung tidak dapat berkata-kata dan lidahnya menjadi kelu.

Makna harfiah shita wo maku adalah menggulung lidah, sedangkan makna metaforisnya adalah terkejut. Shita wo maku merupakan frasa metaforis (vehicle) yang memiliki makna 
metaforis (topic) yaitu terkejut. Hal ini didasarkan pada hubungan antara makna harfiah dan makna metaforisnya yang dihubungkan dengan metafora ontologikal dan metafora struktural.

Metafora ontologikal menjelaskan konsep emosi terkejut sebagai sebuah objek yang dapat mengatur gerakan lidah seseorang. Konsep pemikiran manusia memetakan emosi terkejut

yang sifatnya abstrak dan tidak memiliki acuan menjadi sesuatu yang dapat mengontrol pergerakan lidah seseorang. Lidah menjadi bagian tubuh yang berperan sebagai pengecap dan pelafalan. Lidah dan emosi terkejut memiliki skema citra berupa force dengan ciri enablement. Hal ini dikarenakan lidah sebagai bagian tubuh yang dikontrol oleh emosi terkejut sehingga seseorang kesulitan untuk menggerakkan lidahnya atau berbicara ketika sedang menghadapi hal yang mengejutkan. Jika diterjemahkan secara harfiah, shita wo maku berarti menggulung lidah, menggulung lidah yang dimaksud adalah membuat seseorang kesulitan untuk berbicara karena lidah memiliki peran dalam kemampuan berbicara bagi seseorang. Ketika lidah tergulung, maka lidah tidak dapat bergerak bebas untuk melafalkan kata sehingga tidak dapat mengucapkan sepatah kata pun. Hubungan dari menggulung lidah ini mengakibatkan seseorang tidak dapat berkata-kata ketika sedang merasa terkejut. Oleh karena itu, lidah merepresentasikan emosi terkejut karena emosi terkejut memberikan respon berupa lidah yang menjadi kelu sehingga tidak dapat mengucapkan sepatah kata pun seperti tergulung lidahnya.

Berdasarkan analisis data 8 yang telah diuraikan sebelumnya, dapat disimpulkan bahwa metafora pada idiom shita wo maku memetakan emosi terkejut sebagai emosi yang dapat mengatur pergerakan lidah seseorang sehingga tidak dapat mengucapkan sepatah kata seperti tergulung lidahnya saat menghadapi hal yang mengejutkan

\section{Simpulan}

Berdasarkan pembahasan dari proses identifikasi dan analisis idiom bahasa Jepang yang berkaitan dengan emosi pada kamus Jepang online Goo Jiten menggunakan teori metafora konseptual yang dikemukakan oleh Lakoff dan Johnson (1980) dan teori metafora oleh Knowles dan Moon (2006), dapat disimpulkan bahwa konsep emosi manusia yang bersifat abstrak secara kognitif dipetakan menjadi bentuk yang konkret dengan melibatkan metafora ontologikal sebagai penghubung antara emosi dan idiom yang terbentuk dari unsur anggota tubuh. Berdasarkan dari hasil analisis data yang dikaji dalam penelitian ini, pemetaan kognitif orang 
Jepang memetakan emosi marah yang direpresentasikan dengan bagian perut, dada, kepala; emosi takut yang direpresentasikan dengan bagian tubuh yaitu lidah, hati, dan kaki; emosi senang yang direpresentasikan dengan pipi, dada, dan hati; emosi sedih yang direpresentasikan dengan bagian tubuh yaitu bahu, dada, dan hati; emosi cinta yang direpresentasikan dengan mata dan hati; emosi bangga yang direpresentasikan dengan dada; emosi malu yang direpresentasikan dengan wajah dan pipi; dan emosi terkejut yang direpresentasikan dengan mata, lidah, dan jantung. Pemetaan konsep emosi yang bersifat abstrak ke dalam bagian tubuh bertujuan untuk menunjukkan tingkat emosi yang dialami agar lebih mudah dipahami karena lebih terukur. Hal ini memetakan emosi yang bersifat abstrak sebagai sebuah entitas yang konkret yaitu entitas berupa cairan yang terdapat di dalam wadah atau entitas berupa organ tubuh.

Penelitian ini juga menghasilkan temuan bahwa pemetaan makna idiom yang berkaitan dengan emosi tidak hanya melibatkan metafora ontologikal saja. Metafora struktural dan metafora orientasional juga turut berperan dalam pemetaan makna idiom yang berkaitan dengan emosi. Metafora struktutal berperan dalam pemetaan antara emosi yang bersifat abstrak dengan objek lain yang memiliki kesamaan sifat, sistem, dan struktur. Metafora orientasional berperan dalam pemetaan antara emosi yang bersifat abstrak dengan orientasi spasial yang berhubungan dengan arah.

\section{Referensi}

Tim Penyusun Bahasa. (2008). Kamus Bahasa Indonesia. Jakarta: Pusat Bahasa.

Berendt, E. A., dan Tanita, K. (2011). "The 'Heart' of Things: A Conceptual Metaphoric Analysis of Heart and Related Body Part in Thai, Japanese, and English". Intercurtural Communication Studies XX, 1, 65-78.

Croft, W. dan Cruse, D. A.. (2004). Cognitive Linguistics. Cambridge: Cambridge University Press. Evans, V. (2007). Glossary of Cognitive Linguistics. Edinburgh: Edinburgh University Press.

Glucksberg, S. (2001). Understanding Figurative Language, From Metaphors To Idioms. Oxford: Oxford University.

Goo Jiten. (n.d.). https://dictionary.goo.ne.jp/.

Gruyter, M. D. (2005). From Perception to Meaning Image Schemas in Cognitive Linguistics. Berlin: Division of Walter de Gruyter GmbH \& Co. KG.

Imidas. (n.d.). https://imidas.jp/.

Kotobank. (n.d.). https://kotobank.jp/.

Kovecses, Z. (2004). Metaphor and Emotion Language, Culture, and Body in Human Feeling. Cambridge: Cambridge University Press. 
Kovecses, Z. (2010). Metaphor A Practical Introduction; Second Edition. Oxford: Oxford University Press.

Lakoff, G. dan Johnson, M. (1980). Metaphors We Live By. Chicago: University of Chicago Press.

Malinda, H. K. (2015). Analisis Makna Kanyouku 'Kao' dan Padanannya dalam Bahasa Indonesia. Skripsi Sarjana pada Universitas Negeri Semarang: tidak diterbitkan.

Miswari. (2017). Mengelola Self Efficacy, Perasaan, dan Emosi dalam Pembelajaran Melalui Manajemen Diri. Cendekia, Vol. 15 No. 1, 67-82.

Rachmawati, D. (2019). Metafora Tangan dalam Idiom Bahasa jepang Berdasarkan Teori Metafora Konseptual. Skripsi Sarjana pada Universitas Dian Nuswantoro Semarang: tidak diterbitkan.

Rahmah, Y. (2014). Ungkapan Rasa Terkejut dalam Ragam Kanyouku. Jurnal Izumi, Volume 3 No. 2, 52-60.

Saeed, J. I. (2016). Semantics. Oxford: Blackwell Publisher.

Saifudin, A. (2018). Konseptualisasi Citra Hara 'Perut' dalam Idiom Bahasa Jepang. Japanese Research on Linguistics, Literature, and Culture, Volume 1 No. 1, 65-78.

Saifudin, A. (2012). Metafora dalam Lirik Lagu Kokoro no Tomo Karya Itsuwa Mayumi. Jurnal Lite Bahasa, Sastra, dan Budaya, Volume 8 No. 2, 89-105.

Suciati, R. (2014). Perbedaan Ekspresi Emosi pada Orang Batak, Jawa, Melayu, dan Minangkabau. Skripsi Sarjana pada Universitas Islam Negeri Sultan Sarif Kasim Riau: tidak diterbitkan.

Swasono, RN. dan Saifudin, A. (2013). Makna Idiom Hana dalam Perspektif Budaya Orang Jepang. Prosiding Asosiasi Studi Jepang di Indonesia.

Weblio Jiten. (n.d.). https://www.weblio.jp/. [diakses pada 1 Mei 2020]

Wen, C. (2018). "Nihongo Kanyouku no Kijutsuteki Kihan". Gengogaku Ronsou Online Han, Volume 11 No. 37, 20-46.

Wulansari. (2011). Makna Kanyouku "Ashi" yang Terdapat pada Buku Sanseidou Kanyouku Benran. Skripsi Sarjana pada Universitas Negeri Semarang: tidak diterbitkan. 